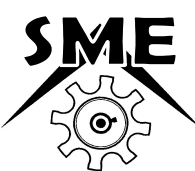

ESTD 2005

\title{
EXPERIMENTAL ANALYSIS ON MECHANICAL PROPERTIES OF NATURAL BIO-POLYMER COMPOSITE
}

\author{
Sudalai Raja A and * Jebakani D
}

Department of Mechanical Engineering, Government College of Engineering, Tirunelveli, Tamil Nadu- 627007, India

\begin{abstract}
Bio-composites are used in many engineering applications due to various desirable properties that they offer such as light weight, low cost, bio-degradable and bio-compatible. Bio-composites are used in many industries such as automotive, sporting goods, marine, electrical and household appliances. Kenaf, jute, banana, flux is used as fibers. The mechanical properties are evaluated by appropriate testing methods. The strength of material is important to each material so that bio-material to be evaluated by mechanical testing methods. In this study an attempt is made to prepare natural resin with neem oil and Thennamarakudi oil and to fabricate Bio-composite with fish shell and screw pine fiber as reinforcement and test for its mechanical properties such as tensile, Impact and Flexural. The pure resin samples have tensile and flexible properties. After taken testing. the neem oil-based biomaterial flexibility is higher than the oil-based biomaterial. The stiffness is higher in Tk oil-based biomaterial. The result is expected from the biomaterial as eco-friendly material and applicable for medical field as biocompatible.
\end{abstract}

Keywords: Neem, Thennamarakudi oil, Fish and Screw Pine Fiber and Mechanical Properties

\section{Introduction}

Polymer whose basis of production is from natural resources both animals and plants are termed as biopolymers. On the other hand, polymers that move with biological structures and asses, supplement or replace any unit of body are termed as biocompatible polymers. The polymers that break down into biologically acceptable molecules are classified as biodegradable polymers. There is an increasing environmental consciousness and awareness of the need for sustainable development that has raised interest in using natural fibers as reinforcements in polymer composites to replace synthetic fibers [1]. The advantage of bio-composite low cost, low density and low abrasive wear of processing machinery [2].

A Composite material is a combination of two or more materials having different composition each material mixed with each other. It has better property than any of the individual components with respect to strength, wear resistance, etc., and also it has high strength to weight ratio, Biodegradability. The reinforcement consists natural fibers or synthetic filler materials. The base matrix consists of polymers which generally hold the reinforcement together. The base matrix material is the main component which binds the fibers and particles together the matrix material is ductile. Neem oil and Thennamarakudi oil was used in resin. Natural Polyester is the base matrix in which fish fiber and coconut fiber were used [3]. Polyester is a category of polymers that contain ester functional group in their main chain.

The biomaterial is made by adding acids and oil has healing property so that it is main advantage for this material as well. The main draw backs of natural reinforced composites are their water sensitivity, poor dimensional stability, poor adhesion to basically all matrices polymers and poor processability at high fiber contents [4]. Some chemical treatments of the natural fiber can help to overcome such drawbacks to enhance the bonding between fiber and matrices [5].

In this project, the resin was prepared and the polymeric sheet has been made. The mechanical testing such as tensile test, impact test and wear testing has been taken by appropriate method [6 \& 7].

\section{Materials and Methods}

\subsection{Matrix Preparation}

Neem or Thennamarakudi oil, Formic acid, Hydrogen peroxide were used in the first step modification. Maleic acid and Morpholine were used for further modification of hydroxylated oil fatty acid in different synthesis schemes. Benzoyl peroxide was used as a radical initiator and $\mathrm{N}, \mathrm{N}$-Dimethyl aniline was

*Corresponding Author-E-mail: jebakani@gcetly.ac.in 
used as accelerator in the curing process. Styrene was used as a monomer.

Hydroxylation of oil was carried out by using $100 \mathrm{ml}$ of oil, $100 \mathrm{ml}$ of $97 \%$ formic acid and $55 \mathrm{ml}$ of $30 \%$ hydrogen peroxide. Ice water bath was used externally to keep the temperature below $40{ }^{\circ} \mathrm{C}$. The reaction was vigorously stirred overnight. The resulting emulsion was poured into a separating funnel and extracted with ether. The aqueous layer was removed. The resulting ether layer was dried over anhydrous sodium sulphate and the ether was removed by a rotator evaporator. The resulting product was hydroxylated oil. The above obtained hydroxylated oil was then reacted with maleic anhydride to get the resin. Morpholine was used as a catalyst.

\subsection{Fibre preparation}

The fiber was collected from Navarai fish and it was also soaked into $2 \% \mathrm{NaOH}$ solution in a water bath, where the temperature was maintained throughout at $22^{\circ} \mathrm{C}$ for $24 \mathrm{~h}$, then washed with distilled water and allow to dry.

The screw pine fiber was collected from screw pine leaves. It was soaked into $2 \% \mathrm{NaOH}$ solution in a water bath, then it will be washed with distilled water and allow to dry.

\subsection{Curing process}

The curing process was carried out in two steps by first mixing the obtained resins with $2 \mathrm{wt} \%$ benzoyl peroxide as the catalyst and $0.5 \quad w t \% \quad \mathrm{~N}, \mathrm{~N}$ Dimethylaniline as the accelerator. And the second step was the addition of $10 \mathrm{ml}$ of styrene and let them cure in room temperature. The glass mould was spread out with silicon oil to the above cured resin, add different weight ratio of the fibres and mix well and then it was poured in to the glass mould, after a few hours we can get a fibre reinforced polymeric sheet.

\subsection{Mechanical testing}

Testing of samples for tensile and flexural were done on Universal Testing Machine and to take impact test, charpy impact testing machine were used.

\subsubsection{Tensile strength test}

The most common specimen for ASTM D638 is $200 \mathrm{~mm} * 20 \mathrm{~mm} * 3 \mathrm{~mm}$. The most common specimen for ISO 527 is the ISO 3167 Type 1A multipurpose specimen. ASTM D882 uses strips cut from thin sheet or film. The most common specimen for ASTM D638 is a constant rectangular cross section, $20 \mathrm{~mm}$ (0.78 inch) wide and $200 \mathrm{~mm}$ (7.874 inch) long. Optional tabs can be bonded to the ends of the specimen to prevent gripping damage.

$$
\sigma=\frac{P \max }{A}
$$

Specimens are placed in the grips of a Universal Test Machine as shown in figure 1 at a specified grip separation and pulled until failure. For ASTM D638 the test speed can be determined by the material specification or time to failure (1 to 10 minutes).

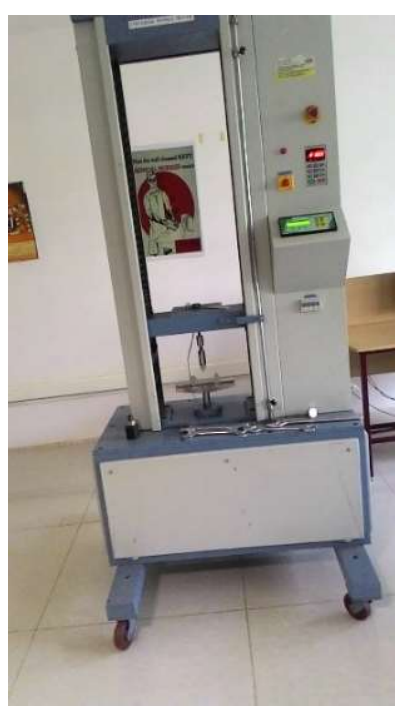

Fig. 1 Universal testing machine

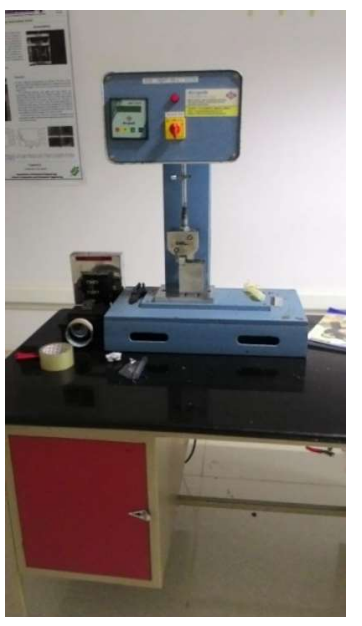

Fig. 2 impact testing machine

\subsubsection{Flexural strength test}

A variety of specimen shapes can be used for this test, but the most commonly used specimen size for ASTM is $3 \mathrm{~mm} \times 13 \mathrm{~mm} \times 127 \mathrm{~mm}(0.118 " \times 0.5 " \times 5 ")$ and for ISO is $10 \mathrm{~mm} \times 4 \mathrm{~mm} \times 80 \mathrm{~mm}$. The equation to find tensile strength is given below.

$$
\xi=\frac{3 P L}{2 b e^{2}}
$$


Most commonly the specimen lies on a support span and the load is applied to the center by the loading nose producing three-point bending at a specified rate. The parameters for this test are the support span, the speed of the loading, and the maximum deflection for the test

\subsubsection{Impact strength test (Unnotched)}

The standard specimen for ASTM is $67 \mathrm{~mm} \times$ $13 \mathrm{~mm} \times 3 \mathrm{~mm}$. The most common specimen thickness is $3.2 \mathrm{~mm}(0.125 \mathrm{inch})$, but the preferred thickness is 3 $\mathrm{mm}(0.3 \mathrm{~cm})$ because it is not as likely to bend or crush. The test specimen has been gripped horizontally on holder as shown in figure 2 . The force will be acted on specimen, which will create break on specimen. The force is obtained by pendulum which has sharp vshaped and more mass.

\section{Result and Discussion}

The importance of mechanical analysis as a tool in the study of the behavior of polymer biocomposites. It has been proved to be an effective method to study the behavior of materials under various conditions of tension, stress, strain, flexible, impact and phase composition of fibre composites and role in determining the mechanical properties.

\subsection{Tensile strength}

The ability of a material to resist breaking under tensile stress is one of the most important and widely measured properties of materials used in structural applications. The force per unit area (MPa or psi) required to break a material in such a manner is the ultimate tensile strength or tensile strength at break. So, the material which is used in this project should be taken from high tensile strength to make high elasticity limit.

\subsection{Flexural strength}

The flexural strength of a material is defined as the maximum bending stress that can be applied to that material before it yields. The most common way of obtaining the flexural strength of a material is by employing a transverse bending test using a three-point flexural test technique. Flexural strength is also known as bending strength, modulus of rupture or transverse rupture strength. If the bio material is having high flexible in their property, which is more useful to obtain for highly elastic ability.

\subsection{Impact strength}

Impact strength is the capability of the material to withstand a suddenly applied load and is expressed in terms of energy. Often measured with the Izod impact strength test or Charpy impact test, both of which measure the impact energy required to fracture a sample. Volume, modulus of elasticity, distribution of forces, and yield strength affect the impact strength of a material.

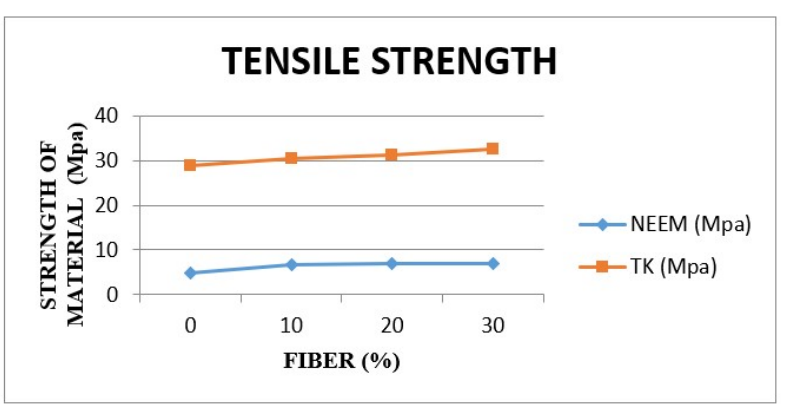

Fig. 3 Tensile strength of Neem and Thennamarakudi (TK) oil-based composite material for various fish fiber reinforcement

Figure 3 shows that, bio-material without fiber is having less strength compared to adding fiber. The tensile strength is increased during various ratio of fiber added into the resin. Tensile strength of Neem oil-based bio-composite material is less compared to TK oil based bio composite material. The tensile strength of biomaterial has increased while adding fiber content in this process.

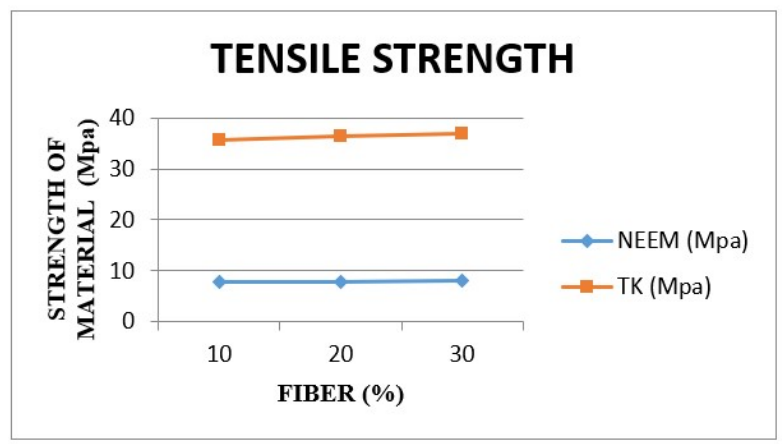

Fig. 4 Tensile strength of Neem and

Thennamarakudi (TK) oil-based composite material for various screw pine fiber reinforcement

Figure 4 shows that, when bio-material is reinforced by screw pine fiber, then strength of material has been increased so that it can be useful to make strong material. Tensile strength of Neem oil-based biocomposite material is less compared to TK oil-based bio composite material. The tensile strength of bio-material has increased while adding fiber content in this process. The elongation is reduced while strength is high. 
Table 1 Tensile property of neem and tk oil based fish fiber reinforced composite

\begin{tabular}{|c|c|c|c|c|c|}
\hline MATERIAL & $\begin{array}{c}\text { FIBER } \\
\%\end{array}$ & $\begin{array}{c}\text { Tensile } \\
\text { strength } \\
\text { (NEEM) } \\
\text { MPa }\end{array}$ & $\begin{array}{c}\text { Tensile } \\
\text { strength (TK) } \\
\text { MPa }\end{array}$ & $\begin{array}{c}\text { \% Elongation } \\
\text { (NEEM ) }\end{array}$ & $\begin{array}{c}\text { \% Elongation } \\
\text { (TK ) }\end{array}$ \\
\hline 1 & $0 \%$ & 4.9 & 28.9 & 18.40 & 16.08 \\
\hline 2 & $10 \%$ & 6.6 & 30.5 & 17.45 & 15.88 \\
\hline 3 & $20 \%$ & 6.9 & 31.3 & 17.05 & 14.66 \\
\hline 4 & $30 \%$ & 7 & 32.5 & 16.64 & 12.78 \\
\hline
\end{tabular}

Table 2 Tensile property of neem and tk oil based screw pine fiber reinforced composite

\begin{tabular}{cccccc}
\hline MATERIAL & $\begin{array}{c}\text { FIBER } \\
\text { \% }\end{array}$ & $\begin{array}{c}\text { Tensile } \\
\text { strength } \\
\text { (NEEM) } \\
\text { MPa }\end{array}$ & $\begin{array}{c}\text { Tensile } \\
\text { strength (TK) } \\
\text { MPa }\end{array}$ & $\begin{array}{c}\text { \%Elongation } \\
\text { ( NEEM) }\end{array}$ & $\begin{array}{c}\text { \%Elongation } \\
\text { ( TK) }\end{array}$ \\
\hline 1 & $10 \%$ & 7.8 & 35.6 & 15.5 & 10.34 \\
2 & $20 \%$ & 7.9 & 36.3 & 15.3 & 10.02 \\
3 & $30 \%$ & 8.1 & 36.9 & 14.5 & 9.11 \\
\hline
\end{tabular}

Table 3 Flexural property of neem and tk oil based fish fiber reinforced composite

\begin{tabular}{ccccc}
\hline MATERIAL & $\begin{array}{c}\text { Flexural strength } \\
\text { ( NEEM) } \\
\text { MPa }\end{array}$ & $\begin{array}{c}\text { Flexural strength } \\
\text { ( TK ) MPa }\end{array}$ & $\begin{array}{c}\text { Flexural strain } \\
\text { (NEEM) } \\
\text { \% }\end{array}$ & $\begin{array}{c}\text { Flexural strain } \\
\text { ( TK) }\end{array}$ \\
\hline $\begin{array}{c}\text { \% } \\
\text { (NEM) }\end{array}$ & 8.5 & 7.2 \\
2 & 32.5 & 25.2 & 7.5 & 7.8 \\
3 & 34.6 & 28.5 & 8.8 & 8.1 \\
4 & 34.9 & 30.3 & 8.9 & 8.4 \\
\hline
\end{tabular}

Table 4 Flexural property of neem and tk oil based screw pine fiber reinforced composite

\begin{tabular}{ccccc}
\hline MATERIAL & $\begin{array}{c}\text { Flexural strength } \\
\text { ( NEEM) } \\
\text { MPa }\end{array}$ & $\begin{array}{c}\text { Flexural strength } \\
\text { ( TK ) MPa }\end{array}$ & $\begin{array}{c}\text { Flexural strain } \\
\text { (NEEM) } \\
\text { \% }\end{array}$ & $\begin{array}{c}\text { Flexural strain } \\
\text { ( TK) } \\
\text { \% }\end{array}$ \\
\hline 1 & 30 & 26 & 7.8 & 6.5 \\
2 & 30.8 & 27.5 & 8.5 & 6.8 \\
3 & 32 & 28 & 8.8 & 7.1 \\
\hline
\end{tabular}

Table 5 Impact property of neem and tk oil-based fish fiber reinforced composite

\begin{tabular}{ccc}
\hline MATERIAL & $\begin{array}{c}\text { Impact strength } \\
\text { (NEEM) } \\
\text { J }\end{array}$ & $\begin{array}{c}\text { Impact strength } \\
\text { ( TK ) } \\
\text { J }\end{array}$ \\
\hline 1 & 1.5 & 1.8 \\
2 & 2.1 & 1.9 \\
3 & 2.5 & 2.8 \\
4 & 2.8 & 3.2 \\
\hline
\end{tabular}


Table 6 Impact property of neem and tk oil-based screw pine fiber reinforced composite

\begin{tabular}{ccc}
\hline MATERIAL & $\begin{array}{c}\text { Impact strength } \\
\text { (NEEM) } \\
\text { J }\end{array}$ & $\begin{array}{c}\text { Impact strength } \\
\text { ( TK })\end{array}$ \\
$\mathbf{J}$
\end{tabular}

\subsection{Flexural test}

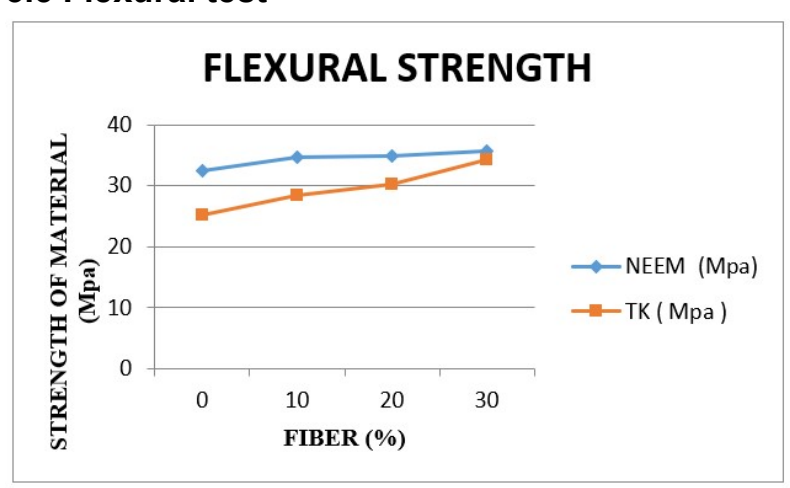

Fig. 5 Flexural strength of Neem and Thennamarakudi (TK) oil-based composite material for various fish fiber reinforcement

Figure 5 shows that, bio-material without fiber is having less strength compared to adding fiber. The flexural strength is increased during various ratio of fiber added into the resin. Flexural strength of Neem oilbased bio-composite material is more compared to TK oil-based bio composite material. The Flexural strength of bio-material has increased while adding fiber content in this process.

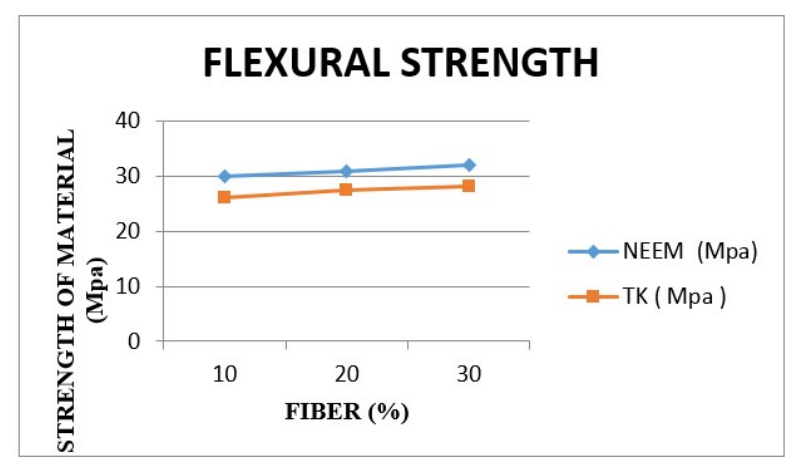

Fig. 6 Flexural strength of Neem and

Thennamarakudi (TK) oil-based composite material for various screw pine fiber reinforcement
Figure 6 shows that, when bio-material is reinforced by screw pine fiber, then flexural strength of material has been increased so that it can be useful to make flexible material. Flexural strength of Neem oilbased bio-composite material is more compared to TK oil based bio composite material. The Flexural strength of bio-material has increased while adding fiber content in this process.

\subsection{Impact test}

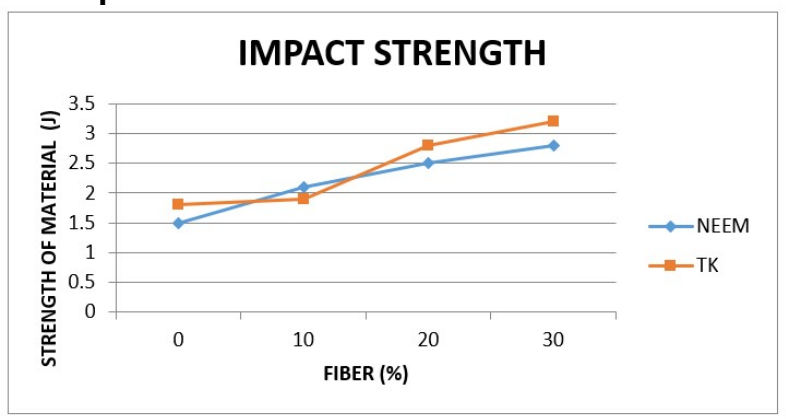

Fig. 7 Impact strength of Neem and Thennamarakudi (TK) oil-based composite material for various fish fiber reinforcement

Figure 7 shows that, Impact strength of Neem oil-based bio-composite material is more compared to TK oil-based bio composite material. The Impact strength of bio-material has increased while adding fiber content in this process.

Figure 8 shows that, while screw pine fiber reinforced bio-material is testing to evaluate impact strength, the neem based oil material is more compared to TK oil based composite material.at maximum fiber reinforcement. The screw pine fiber is increasing that impact strength of bio-material while increasing fiber content so that it can be able to make resistance of high damage on material like fish fiber reinforcement.

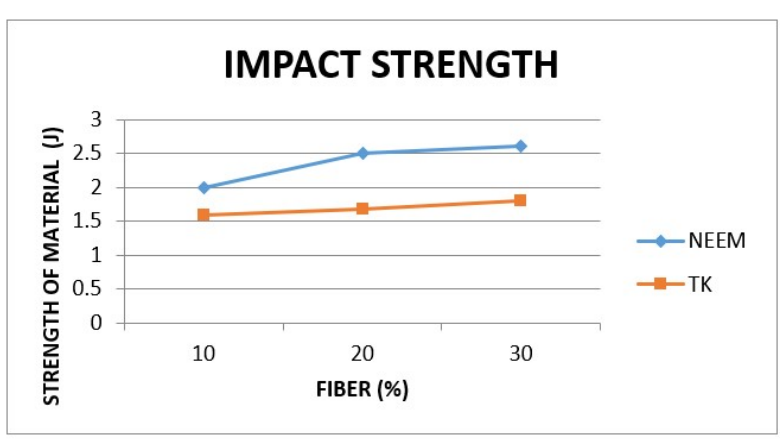

Fig. 8 Impact strength of Neem and

Thennamarakudi (TK) oil-based composite material for various screw pine fiber reinforcement 


\section{Conclusion}

The mechanical properties were taken by mechanical testing such as tensile test, flexural test and impact test. Neem oil and TK oil-based composites were prepared and different ratio of fiber were added and mechanical testing has been taken for that composite or polymeric sheet. The property of bio material has been found by using that testing. The neem oil based polymeric material more flexible compared to Thennamarakudi oil based bio material. The Tk oil based bio material more tensile strength than Neem oil based bio material. The fish and screw pine fiber are increasing material strength were found by taken mechanical testing. The strength was increased during fiber content is added into the matrix 0-30\% fiber content polymer sheets has been made in this project. The maximum fish or screw pine fiber content $30 \%$ polymer sheets have high strength on both neem and tk oil based bio-material.

\section{References}

1. A S Singha and Vijay Kumar thakur (2008), Mechanical properties of natural fibre reinforced polymer composites, Bulletin of Materials Science volume, vol. 31: 791.
2. Easwara Prasad G L, Keerthi Gowda B S and Velmurugan R (2016), A study on impact strength characteristics of treated and untreated sisal polyester composites, Procedia Engineering, vol. 173: 771-778

3. Mulinari, D.R, Baptista, C.A.R.P.b, Souza, J. V. C, Voorwald and H.J.C (2010), Mechanical Properties of Coconut Fibers Reinforced Polyester Composites, Procedia Engineering, vol. 8: $1390-1403$.

4. S. Sathish, K. Kumaresan, L. Prabhu, S. Gokulkumar, S. Dinesh and N. Karthi (2018), Experimental Testing on Mechanical Properties of Various Natural Fibers Reinforced Epoxy Hybrid Composites, International Journal of Pure and Applied Mathematics, Vol. 11: 1-6

5. Takashi Nishinoa, Koichi Hirao, Masaru Ko-tera,Katsuhiko Nakamae, Hiroshi Inagaki (2009), Kenaf re-inforced biodegradable composite, Composites Science and Technology, vol. 764: 10-16.

6. Marie Bayart, Florent Gauvin, M. Reza Foruzanmehr, Saïd Elkoun, and Mathieu Robert (2017), Mechanical and Moisture Absorption Characterization of PLA Composites, Fibers and Polymers, Vol. 18: 1288-1295

7. N.A. Wright1 and S.N. Kukureka (2003), Wear testing and measurement techniques for polymer composite gears, Wear, Vol. 251: 1567-1578 